https://doi.org/10.32735/S0718-2201201900048627

$215-228$

FUNDAMENTOS EPISTEMOLÓGICOS DE LA DOCTRINA GALÉNICA DE LAS ENFERMEDADES DEL ALMA

Epistemological foundations in galenic doctrine for the diseases of the soul's diseases

TERESA GARGIULO

Universidad Nacional de Cuyo (Argentina) gargiulomteresa@gmail.com

\title{
INTRODUCCIÓN
}

Recientes publicaciones testifican el florecimiento actual de los estudios en torno a la obra de Galeno. Cabe destacar el esfuerzo mancomunado de diversos especialistas por dilucidar su doctrina acerca de las enfermedades del alma atendiendo puntualmente a la relación entre moral y fisiología. Se advierte en ello una continuidad hermenéutica que erige esta relación como el punto medular que permite resolver la cuestión acerca del estatuto epistemológico de la doctrina galénica acerca de las enfermedades del alma. Desde este punto de análisis se abren interrogantes como ¿las enfermedades del alma son entendidas por Galeno desde una dimensión exclusivamente ética?, ¿su práctica médica tiene algún tipo de competencia en su estudio?

Buscando dar una respuesta a estos interrogantes objetaremos, particularmente, aquella tradición hermenéutica que sitúa su doctrina acerca de las enfermedades del alma en una dimensión exclusivamente moral.

Entre los autores más representativos de esta línea moralista de interpretación se inscriben los trabajos de García Ballester (1972, pp. 101-102, 133-134; 1993; 1996; 2002), donde argumenta que cuando Galeno aborda la cuestión de las afecciones morbosas del alma no lo hace con un interés médico sino desde un acercamiento estrictamente moral. Los dos tratados acerca de la manera de curar las enfermedades del alma-Diagnóstico y tratamiento de las pasiones del alma de cada uno; Diagnóstico y tratamiento de los errores del alma de cada uno- no son-según Ballester-parte de su doctrina médica sino que más bien componen su obra de corte filosófico. En continuidad con esta línea de lectura, es importante citar los trabajos de López Piñero y Morales $(1966 ; 1967 ; 1970)$, quienes aseguran que el Médico de Pérgamo no desarrolla propiamente una doctrina acerca de una patogenia psíquica y ello mismo explica la ausencia de una verdadera propuesta psicoterapéutica en su obra.

A nuestro entender, este tipo de análisis puede ser correcto en la medida que la regulación moral de las pasiones es parte constitutiva de la terapia galénica. No obstante, supone una lectura incompleta si se advierte que las consideraciones galénicas de tipo moral se insertan en una concepción aún más compleja de los males del alma. Galeno lejos de reducir su propuesta psicoterapéutica a una perspectiva moral o psicologista, la integra en un modelo anatomopsicofisiológico que excede las 


\section{Teresa Gargiulo}

coordenadas estrictamente morales en los que estaba interesada principalmente la filosofia de su época.

Nuestra investigación se desarrolla en consonancia con recientes publicaciones que han mostrado suficientemente la continuidad que existe entre los escritos galénicos de tono moral y sus obras de carácter clínico. Se trata de la tradición hermenéutica inaugurada por Véronique Boudon-Millot (2009), quien se ha ocupado de mostrar cómo los ideales éticos de Galeno fundan y atraviesan tanto sus ideas médicas en torno a la especie humana como su misma práctica científica. Esta misma línea de investigación ha sido fortalecida por los trabajos de Liliana Molina González (2012) y por Rosa Moreno Rodríguez (2013). Nuestro trabajo se desarrollará en relación con el horizonte comprensivo ya planteado en estos últimos trabajos. En este sentido, el valor del presente estudio no radica en la originalidad o la novedad de su tesis, sino más bien en la sistematización o precisión con la que se busca definir el estatuto epistemológico de la doctrina galénica acerca de las afecciones del alma.

El objetivo de nuestro trabajo es postular una particular sistematización de la doctrina galénica acerca de las enfermedades del alma en orden a mostrar que ella no es objeto de un interés exclusivamente moral sino materia de su misma práctica médica.

Para ello analizaremos tres tesis que justifican a su vez la división del artículo. En primer lugar, argumentaremos que en razón de la comprensión hilemórfica que tiene Galeno acerca del hombre, pueden predicarse al alma aquellas enfermedades mentales que afectan primaria y principalmente al cuerpo con una disfunción humoral. Presentaremos al alma como sujeto per accidens del enfermar (1). En segundo lugar, estudiaremos al alma como el sujeto propio de la enfermedad. Esta tesis se sustenta en aquellos textos donde Galeno concibe las facultades anímicas como los agentes patógenos primarios del enfermar (2). Finalmente, analizaremos la naturaleza moral y cognitiva de los agentes a-somáticos que se erigen para Galeno en posibles causas etiológicas del enfermar humano (3).

El orden expositivo de nuestro trabajo no busca respetar un orden estrictamente cronológico. La exposición es más bien hermenéutica y comprensiva. A saber, buscamos que quede patente -en el análisis de estas tres tesis- el fundamento del particular abordaje epistémico de Galeno respecto de las afecciones anímicas.

\section{EL ALMA COMO SUJETO DEL ENFERMAR PER ACCIDENS}

Antes de esclarecer los diferentes niveles explicativos de su doctrina acerca de la enfermedad del alma mencionaremos, en líneas generales, qué entiende Galeno por enfermedad.

Galeno define la enfermedad como una disposición preternatural del cuerpo (diáthesis para physin) por la que se ven impedidas sus funciones vitales. El organismo en su condición de enfermedad padece la destitución de su disposición connatural. La enfermedad es una pasión. Por pathos, el médico (2015) entiende aquel movimiento que es contrario a la naturaleza. Ilustra estas consideraciones con los movimientos del 
corazón. Explica que la pulsación es el movimiento propio del corazón y por eso es su energeia propia: tiene su origen en él y es acorde con su naturaleza. Sin embargo, no todo tipo de pulsación es energeia porque este movimiento puede verse afectado por un cambio en las condiciones fisiológicas del cuerpo. Una pulsación acelerada o muy lenta no es propia del corazón en estado normal. En cuanto la pulsación se torna inmoderada o excesivamente débil, dicho movimiento se convierte en un movimiento contrario a su naturaleza. Dicha pulsación, entonces, sería pathos y no la energeia propia o el movimiento natural del corazón. La pulsación se convierte así en un agente patógeno en cuanto que produce una alteración tal del organismo o de alguna de sus partes que lo aleja de su disposición natural.

El término pathos en la obra de Galeno tiene una doble acepción. Por un lado y de un modo genérico con él se refiere a todo aquello que nos sucede o afecta. Pero en ciertos pasajes dicho término debe ser traducido como enfermedad o afección, a saber, en la medida que se trata de un movimiento contrario a la naturaleza propia de una función. En la enfermedad la facultad ya no realiza su función de forma activa sino que su movimiento está sometido o es pasivo de los agentes morbosos. En el estado morboso hay una cierta permanencia, por la que el organismo se ve privado de la ordenación propia y regular de su propia naturaleza.

Ahora bien, la definición de enfermedad como una diáthesis para physín ha sido un enérgico argumento esgrimido por García Ballester para concluir que Galeno concibe al cuerpo como el sujeto propio de la enfermedad. Traduce la noción de physín de un modo materialista, por lo que solo resultaría enfermable -en un sentido propio- lo somático. Luego, concluye que es ilegítimo adjudicar a Galeno una doctrina acerca de las enfermedades del alma. García Ballester (1972, p. 100) alega que cuando el médico romano griego en su escrito De differentiis morborum distingue los cuatro modos o géneros de enfermedad, no hace ningún tipo de consideración respecto de los géneros del enfermar del alma. Luego, el alma no parecería sujeto pasible de enfermedad. Fuera del cuerpo no podría haber enfermedad propiamente dicha. Para validar esta misma conclusión el autor cita también el epígrafe Sex res non naturales, donde se estudian las seis cosas no naturales que constituyen las posibles causas externas de la etiopatología galénica (aire y ambiente, comida y bebida, trabajo y descanso, sueño y vigilia, excreciones y secreciones, y, finalmente, los movimientos o afectos del alma). Con el análisis de este epígrafe Ballester quiere mostrar que los afectos del alma son estudiados por Galeno como una causa exterior del enfermar humano. Los afectos y las emociones no son sujeto de enfermedad sino que pueden ser causa de un movimiento humoral que tiene una repercusión patológica sobre el cuerpo.

Dando un paso más, García-Ballester (1972, pp. 101-102) termina por establecer una dialéctica entre las obras clínicas y aquellas de carácter ético. A estas últimas, según él, quedaría reducido el abordaje que hace Galeno de las afecciones anímicas.

Por nuestra parte podemos decir que el primer obstáculo que encontramos en la traducción y reducción de la physin al soma son todos aquellos escritos donde Galeno 
desarrolla su concepción hilemórfica de la naturaleza humana. Esta concepción hilemórfica -que ha sido suficientemente explicitada por Moreno Rodríguez (1983; 2013) - nos permite entender que el sujeto de la enfermedad no es solamente el cuerpo. Lo que se enferma es la physis del hombre, todo el hombre: su cuerpo y su alma.

En Quod Animi Mores Corporis temperamenta Sequntur (2003) y en De Placitis Hippocratis et Platones (2015), el médico de Pérgamo presenta el alma como el conjunto de facultades y funciones que depende de la organización estructural de los seres vivientes. El alma es la causa formal de la vida que se manifiesta en la estructura material del cuerpo. Alma y cuerpo son para el médico principios constitutivos de una totalidad indiferenciable. Insiste que las facultades del alma no pueden ser reducidas a la complexión humoral del cuerpo. Las facultades se relacionan con las mezclas humorales específicas de cada órgano como la forma respecto de la materia. A saber, se distinguen aunque guardando siempre una unidad ontológicamente funcional.

Ahora bien, estos textos donde el médico expone su concepción hilemórfica de la naturaleza humana nos permiten un acercamiento más profundo a su noción de enfermedad; y advertir el recorte ontológico que supone traducir o identificar su concepto de physin con el de soma. Pues si el alma constituye una unidad ontológica con el cuerpo entonces debe admitirse que ella también puede ser accidentalmente sujeto del enfermar.

Es importante destacar que a pesar de la comprensión hilemórfica de la physis humana, Galeno no desarrolla ni permite ciertas preguntas que podrían resolverse en línea con esta doctrina. Por ejemplo, en numerosos pasajes del De Placitis Hippocratis et Platones (2015) asegura que no le interesa resolver en absoluto la cuestión de si alma, como principio formal del cuerpo, es inmortal. ${ }^{1}$ Él podría haber dado un paso especulativo más y sostener no solo que el alma es la forma del cuerpo sino también que ella es en sí misma incorruptible e inmune a las corrupciones o mutaciones humorales -así como hizo más tarde el cristianismo ${ }^{2}$. Pero no lo hizo. Evitó explícitamente inferir este tipo de conclusiones en cuanto que las consideraba irrelevantes para su práctica médica. Y ello - como veremos más adelante- nos da una pista acerca de dónde quiere situar el estatuto epistemológico de su tratamiento acerca de las enfermedades del alma.

No obstante, en cuanto que Galeno reconoce al alma como la forma de un cuerpo -tesis que ciertamente afirma- abre la posibilidad de que ella pueda accidentalmente corromperse o enfermarse. En razón de su unidad sustancial con el cuerpo puede decirse

\footnotetext{
${ }^{1}$ García-Ballester (1996, pp. 711 y ss) presta particularmente importancia a estos textos donde Galeno es reticente a dar una respuesta en este sentido.

${ }^{2}$ Tomás de Aquino en continuidad con esta tradición galénica, da este paso especulativo. Explica que el alma en sí misma es incorruptible. No puede corromperse ni en sí misma (per se) ni en función de otro corruptible del que dependa (per accidens). Es imposible la corrupción del alma por sí misma, ya que es simple. Tampoco puede corromperse accidentalmente porque no depende del cuerpo para existir. Cf. Suma contra Gentiles, L, II, C., LV.
}

218 | ALPHA No48 (2019) PÁGS. 215-228. ISSN 0716-4254 
que ella accidentalmente está enferma. Pues a causa de una alteración humoral, ella se encuentre impedida a ejercer sus funciones o facultades (dynamis).

Ciertamente, hay enfermedades en las que el sujeto propio es el cuerpo. Este es el caso de las enfermedades mentales, las que suponen primariamente una lesión orgánica. De dicha perturbación -explica el médico- se sigue un impedimento para el correcto uso de las facultades del alma, sea de la memoria, la inteligencia o el movimiento voluntario. El daño en las funciones o dynamis psíquicas tiene un origen físico, es decir, es causado por alteraciones en las krasis humorales del cuerpo: "Una complexión humoral cálida - escribe- vuelve irascible y la irascibilidad inflama el calor innato; los que tienen una complexión humoral equilibrada tienen los movimientos del alma moderados" (Galeno, 2003, p. 17).

En Sobre los lugares afectados Galeno (1997a) explica que como existen muchas diferencias de grado en la humedad y el frío, así como en la sequedad y el calor, suceden una variedad múltiple de causas que lesionan las facultades psíquicas. Aún más, detalla de un modo específico la etiología de las enfermedades mentales según sea la mala krasis de humores que perturba funcionalmente a una facultad. Allí explica que la demencia (morosis) y la amnesia (lethe) deben ser comprendidas como un enfriamiento de la krasis del cerebro, así como las apoplejías y las epilepsias como una concentración excesiva de flema en las cavidades del cerebro. La melancolía, en cambio, tendría por causa la acumulación de un humor frío. La disfunción humoral es la causa de la alteración, debilitamiento o pérdida de las facultades mentales como la memoria y el entendimiento, así como sucede en los casos de melancolía, frenitis y manía. Kakochimia es el concepto con el que Galeno (2003) indica que ciertos males del alma tienen su causa en una mala mezcla de los humores del cuerpo.

La enfermedad mental sin dejar de ser una disfunción humoral afecta per accidens al ejercicio de la facultad correspondiente al órgano afectado. $Y$ en este sentido es lícito referirse a ellas como enfermedades del alma. Para en este caso lo que padece per sé es siempre el cuerpo. En este sentido, a la luz de la comprensión hilemórfica que tiene Galeno, es legítimo sostener que el alma es sujeto pasible per accidens de la enfermedad mental.

\section{EL ALMA COMO SUJETO PROPIO DE LA ENFERMEDAD}

Ahora bien, es impotrtante destacar que el médico-filósofo también reconoce como enfermedades del alma a desequilibrios que no son primariamente y en cuanto tales humorales, sino que tienen una sintomatología orgánica. En este sentido, predica la noción de pathos a diversos agentes de carácter psíquico, cognitivo y moral que pueden significar una disfunción en el organismo humano. En un lenguaje aristotélico podríamos decir que a pesar del carácter a-somático, intencional o anímico de estos agentes los reconoce como sujetos pasibles del enfermar en cuanto que se constituyen como la causa propia de una concomitante disfunción humoral. Se trata de movimientos 


\section{Teresa Gargiulo}

anímicos que están siempre acompañados, como de su principio material, por una transmutación orgánica que puede provocar una disfunción humoral.

En el siguiente texto Galeno parece delimitar taxativamente el objeto epistémico que le compete tanto al filósofo como al médico. Mientras el primero debe ocuparse de modelar las costumbres del alma, el médico debe atender al cuerpo:

Según el filósofo solo hay que modelar las costumbres del alma, pero el médico debe atender el cuerpo (...) La ira, el llanto, la cólera, el dolor, una preocupación innecesaria o el insomnio desarrollan en los cuerpos la fiebre y originan grandes enfermedades. De este modo, se producen pereza del pensamiento y necedad (Galeno, 2016, p. 87).

Sin embargo, unas líneas más adelante explica que las mismas pasiones o disposiciones psíquicas pueden provocar grandes enfermedades. Esta disquisición es la que nos permite inferir el aspecto formal desde el que sería legítimo, según él, que el médico también investigue lo que en principio es objeto del filósofo o moralista. Las disposiciones psíquicas o costumbres del alma sea la cólera o la ira también son objeto de su incumbencia en tanto y en cuanto ellas pueden ser causa de una disfunción humoral que afecta a la salud del cuerpo.

En Symp. Diff Galeno (1997a) distingue la enfermedad de sus síntomas. Define la enfermedad como la causa que primariamente impide realizar una función. El síntoma, en cambio, es el mismo daño o alteración de la función. También en Ars. Med. 307-310 asegura que el médico debe conocer no solo la composición humoral de las partes del cuerpo, sino también las causas de sus disfunciones. Luego, al médico en cuanto médico le compete estudiar las afecciones del alma en la medida que ellas pueden ser causa primaria de una ruptura de la armonía de los componentes humorales del cuerpo humano. En este sentido, las pasiones son concebidas por él no como sujetos per accidens sino como sujetos propios del enfermar humano.

Las causas procatárticas o agentes morbosos que dañan una determinada función pueden ser -al entender de Galeno- de carácter físico o psíquico:

Vamos a estudiar en este tratado las causas de los síntomas siguiendo un orden extraído de las diferencias que hay entre ellas. Hay únicamente tres géneros de síntomas y el primer razonamiento está basado en el primero de estos géneros, que decimos ser el daño de la función. Pero las funciones son dos según el tipo de su sustancia: físicas y psíquicas (Galeno, 2016, p. 17).

De acuerdo con estos dos textos podríamos decir que en la medida que el espíritu y el psiquismo humano se comportan como causas primarias del enfermar se les puede predicar con propiedad el concepto de enfermedad.

En este marco hermenéutico puede entenderse cuando Galeno (2015) concibe la ira como una enfermedad del alma, sin que ello suponga una contradicción con la definición de enfermedad expuesta en sus escritos clínicos. Las pasiones producen alteraciones fisiológicas en el órgano que tienen como sede y a partir de ese movimiento 
se siguen otros efectos corporales. Las alegrías provocan una dilatación del corazón, la tristeza una contracción. La ira, por su parte, produce una gran pulsación en el movimiento de las arterias. En cuanto que el alma inicia con sus respectivos movimientos de las pasiones dichas alteraciones, se dice que ella padece en un sentido propio una enfermedad.

Las pasiones pueden llevar a la enfermedad del mismo modo que las pasiones físicas, en la medida que ellas suponen con sus excesos una alteración negativa y perjudicial de las cualidades sensibles de los órganos. La ira y el miedo - explica Galeno (2015) - producen una alteración en la acción natural del corazón. Fisiológicamente la primera puede ser descrita como una ebullición de calor del corazón mientras el miedo se manifiesta como un enfriamiento corporal.

Las pasiones son reconocidas como patológicas en la media que suponen una alteración, remoción o pérdida de un orden o proporción. Las emociones son el movimiento natural, la energeia propia del apetito irascible y concupiscible. Pero en la medida que estas son excesivas o inmoderadas constituyen una verdadera afección (pathos) de estas facultades del alma y de todo el cuerpo. Pues debido a su falta de mesura se tornan movimientos contrarios a la naturaleza de esa parte del alma. Galeno (2015) sostiene que descubrir cuál es la causa de las afecciones del alma nos ayuda a comprender qué significa vivir de acuerdo con la naturaleza..

La enfermedad que se explica etiológicamente por el desorden de las pasiones tiene como sujeto la misma alma. Pues ella es la que propiamente padece el conflicto pulsional entre sus partes. La actividad o la dynamis exacerbada de una de sus partes supone la afección de las otras facultades del alma. Por ejemplo, la fuerza de la ira supone una afección de la parte racional (Galeno, 2015, p. 45). ${ }^{3}$

En muchas ocasiones la razón es tan fuerte sobre la parte tímica del alma que nunca se produce un conflicto entre ellas, la una dirige, la otra es dirigida. Este es el caso de las personas que se han dedicado a la filosofía. En otros casos, la ira es tan fuerte en relación con la razón que llega a dominar y gobernar todo, como es visto que les sucede a muchos bárbaros (Galeno, 2015, p. 48).

La comprensión galénica de este tipo de afección supone no solo la concepción tripartita del alma sino también la división anatómica de sus partes o funciones.

Si la salud del cuerpo es la proporción entre sus partes simples (...), es decir calor, frialdad, sequedad y humedad, supongo que la salud del alma será la proporción entre sus partes más simples. Tú, [Crisipo] si quieres cumplir con toda tu promesa [la curación de las afecciones del alma] debes desarrollar cuáles son estas partes, cuántas y cómo se relacionan entre sí, pues la enfermedad del alma es una

\footnotetext{
3 "En muchas ocasiones la razón es tan fuerte sobre la parte tímica del alma que nunca se produce un conflicto entre ellas, la una dirige, la otra es dirigida. Este es el caso de las personas que se han dedicado a la filosofía. En otros casos, la ira es tan fuerte en relación a la razón que llega a dominar y gobernar todo, como es visto que les sucede a muchos barbaros".
} 
desproporción y un conflicto mutuo (stásis) entre las partes que mantienen la salud del alma (Galeno, 2015, p. 44).

Galeno (2015) distingue ontológica, anatómica y fisiológicamente las partes del alma. A la facultad concupiscible la localiza en el hígado y le adjudica las funciones e impulsos que se ordenan a la nutrición, y reproducción. A la tímica, la sitúa en ventrículo izquierdo del corazón pues en este se presentan las manifestaciones fisiológicas de las emociones. A la facultad racional le asigna como sede el cerebro pues de él dependen -según sus observaciones- las funciones motora, sensitiva e intelectual.

Tal como consta en PHP Galeno (2015) establece la disección anatómica como el método que permite discriminar la sede orgánica de las facultades del alma junto con sus respectivas funciones. Según este deben examinarse las propiedades y atributos de las principales partes del cuerpo, observando particularmente qué sucede con ellas cuando se alteran sus actividades, ya sea presionando o infringiendo heridas. De este modo, aquella realidad que podría o no, ser a-somática -tesis que Galeno no está interesado en resolver y que aparentemente escaparía a la competencia de su estudiose manifiesta y estudia en la organización anatómica y funcional del cuerpo.

Pero dicha división anatómica no es óbice para que Galeno entienda la salud del alma como una relación armónica y funcional. El texto recién citado puede señalarse como la definición específica de enfermedad del alma a la que accede Galeno. Las afecciones anímicas no son sino una desproporción y un conflicto mutuo entre sus partes. De aquí que cuando exista un conflicto pulsional entre sus partes debe predicarse al alma, en un sentido propio, el concepto de enfermedad.

\section{LANATURALEZA MORAL Y COGNITIVA DE LAS CAUSAS ETIOLÓGICAS PROPIAS DEL ENFERMAR HUMANO}

En el primer punto explicamos cómo el alma se constituye en sujeto accidental del enfermar humano mediante una tesis que Galeno desarrolla ampliamente en su tratado Quod animi mores corporis temperamenta sequntur. A saber, que las manifestaciones psíquicas del hombre pueden ser explicadas partir de esquemas fisiológicos de su doctrina humoral. En el segundo apartado, hemos visto que los movimientos anímicos también son considerados, en ciertos casos, como la causa propia del enfermar anímico. El médico trasciende los esquemas de un corporalismo naturalista e invierte el enfoque de análisis de la patología psíquica: es decir, ya no muestra la dependencia de la vida moral y las manifestaciones psíquicas del estado humoral, sino que abre la consideración de las disposiciones psíquicas, cognitivas y morales como causas etiológicas primarias de las afecciones anímicas. En este último apartado veremos más pormenorizadamente -como lo muestra en Diagnóstico y tratamiento de las pasiones del alma de cada uno; Diagnóstico y tratamiento de los errores del alma de cada uno- la naturaleza moral y cognitiva de estos agentes asomáticos que se erigen para Galeno en causas etiológicas del enfermar humano. 
Para poder explicar el origen de la disfunción provocada por las pasiones Galeno (2015) se remonta a una etiología de carácter moral. Señala la akrasía, es decir, la falta de dominio sobre las pasiones como el inicio de este tipo de enfermedades. ${ }^{4} \mathrm{O}$ dicho en otros términos: el deseo insaciable de dinero, gloria, honores, poder, discusiones y discordia es reconocida por Galeno (1997c) enfermedades del alma y la condición fundante de su enfermar. Aún más, la presenta como la causa de todas las tristezas o aflicciones del alma. Pues al tratarse de deseos insaciables, es decir, de deseos que por su mismo carácter resultan insatisfechos, surge en el alma la tristeza. "Los insaciables escribe-ambicionan siempre lo que está delante de sí, de suerte que si tienen el doble ansían adquirir el triple, y si tienen el triple, exige el cuádruple" (Galeno, 1997c, p. 49). El alma al no poseer la autarquía padece las pasiones o afecciones que se siguen de sus deseos insatisfechos.

No obstante, Galeno (2015) se aleja de la visión excesivamente moralista que tiene el estoicismo acerca de las pasiones. Objeta particularmente la definición de pasión de Crisipo, quien desde una visión homogénea del alma la entiende como un movimiento excesivo de la razón que desobedece la norma y medida propia de la racionalidad. No sin cierta ironía el médico le señala a Crisipo la contradicción de introducir en el alma racional un juicio sin razón y sin juicio. Crisipo -al entender del médico de Pérgamo- no distingue la razón y la pasión como dos facultades ontológicamente distintas, pues esto podría significar un menoscabo de la responsabilidad humana sobre las pasiones. En cambio, si las pasiones dependen causalmente del ejercicio de nuestra razón, entonces cada uno de los movimientos de las pasiones supone el libre asentimiento de nuestra razón, el que evidentemente cae bajo nuestra responsabilidad. A diferencia de Crisipo, Galeno (2015, p. 27) comprende las pasiones en continuidad con el Estagirita: las define como movimientos que desobedecen los juicios de la razón pero su causa reside en la facultad irascible del alma, sobre la que el hombre tiene un dominio político pero no despótico.

Esto nos ofrece una prueba más de que el foco de Galeno no está puesto únicamente en determinar la moralidad de los actos humanos sino en analizar fundamentalmente la estructura y naturaleza del alma, para ello recurre constantemente al estudio anatómico y fisiológico de sus facultades.

Pero no solo las pasiones del apetito sino también los juicios o creencias del alma son pasibles de enfermar. En PHP Galeno (2015) admite dos tipos diferentes de afecciones del alma: los juicios errados y las pasiones.

Ciertamente Galeno (1997d) en De Animi Cuiuslibet Peccatorum Dignotione et Curatione se refiere en un sentido amplio a las pasiones como parte de los errores morales. Pues las pasiones exacerbadas - sea el amor propio, la vanidad, la presunciónson en cierto modo errores que conducen al alma a opinar precipitadamente acerca de

\footnotetext{
${ }^{4}$ La falta de dominio sobre las pasiones es comparada por Galeno (2015) con la falta de tonos o fuerza en el alma. Explica que así como se dice que un cuerpo vigoroso tiene buen tono, de modo análogo el alma tiene buen tono si tiene fuerza y dominio sobre sus pasiones y deseos.
} 


\section{Teresa Gargiulo}

bienes y males, es decir, sin tener ningún tipo de convicción en su opinión. Pero seguidamente explica que no es a este tipo de error al que se refiere específicamente. Él denomina error en sentido estricto a aquellos juicios sobre bienes y males que se deben no a un desorden de las pasiones sino a una falla en el razonamiento del logos. Estos juicios erróneos manifiestan una falta de entrenamiento del entendimiento para distinguir entre argumentos verdaderos, falsos y probables. Logos y pathos se le presentan como causas diferenciables de la enfermedad del alma.

Los errores consisten en un mal razonamiento o juicio de valor sobre el bien o el mal de un objeto, persona o circunstancia, pero particularmente se refiere a un juicio errado respecto del fin de la vida. "El origen de muchos errores es una suposición falsa sobre el fin de la vida. En ella se originan los errores individuales como de una raíz" (Galeno, 1997d, p. 77). Esto es lo que lo lleva a inscribir como una obligación del médico el diagnóstico de este tipo de ideas o errores. El médico debería considerar como parte de su tarea, no solo descubrir la idiosincrasia del paciente, sino también averiguar qué es lo que oprime su mente. Pues la cura de una persona cuya enfermedad se ha originado en su mente solo puede lograrse mediante la remoción de la idea fija, y no por medio de la comida y la bebida, condiciones de vida, baños, paseos y cosas por el estilo.

La materia fundante de todos los tipos de errores que pueden convivir en un alma enferma es aquel error cognitivo que se pronuncia respecto de los "mayores bienes" de la vida. En este sentido, Galeno (1997d) juzga como indispensable para poder elegir una forma de vida conforme a nuestra naturaleza racional instruirse en el método lógico o demostrativo.

Cuando el médico filósofo (1997d) quiere referirse a un juicio errado acerca de la finalidad de la vida -es decir, a lo que él entiende por error en un sentido estricto- usa propiamente el término de hamartemata. Con él se refiere a las afecciones que padece el logistikon, es decir, errores de tipo intelectual acerca de la finalidad de la vida que traen como consecuencia un desorden moral en el sujeto que los padece. ${ }^{5}$ Por ejemplo, la opinión de que el dinero es un bien no es un hamartemata, sino la opinión según la cual el dinero es el mayor bien o no vale la pena vivir sin dinero (Galeno 2015, p. 25). En este sentido la avaricia se presenta no solo como un movimiento de la pasión sino fundamentalmente como un juicio errado: como la falsa suposición de que el dinero es el mayor bien.

Finalmente, Galeno reconoce a los mismos hábitos y costumbres humanas como sujetos pasibles de enfermedad. Las pasiones pueden ser solo el estado inicial de un vicio. Pero si no se curan adecuadamente los excesos de las pasiones estas devienen con el tiempo en hábitos incorregibles, formas de actuar fundadas en creencias y opiniones erradas que son reconocidos por Galeno como verdaderas

\footnotetext{
${ }^{5}$ También se refiere a ellos con el término $\pi \alpha \rho o ́ \rho-\alpha \square \mu \alpha, \alpha \tau o \zeta$, que se puede traducir como equivocación, yerro, cosa mal vista. Esta palabra está a su vez emparentada con el verbo $\pi \alpha \rho o ́ \rho \alpha \sigma \iota \varsigma, ~ \varepsilon \omega \varsigma$ que alude a la acción de ver superficial o confusamente. Парори́́ es mirar de reojo, con indiferencia o descuido.
}

224 | ALPHA №48 (2019) PÁGS. 215-228. ISSN 0716-4254 
"enfermedades" del alma. Se trata de un estado morboso del alma o arrostemata que no es sino el estado de un vicio moral incurable. ${ }^{6}$ Podemos advertir aquí una especie de estratificación de los desórdenes pasionales que va de los episodios excepcionales de pasión exacerbada a hábitos inveterados de conducta no tratados a tiempo que Galeno reconoce como enfermedades incurables del alma.

La posibilidad de curar los excesos de las pasiones disminuye en la medida que avanza la edad del paciente. En su breve escrito titulado Diagnóstico y tratamiento de los errores del alma el médico (1997d) insiste en tres oportunidades en este aspecto. Al comenzar el tratado explica que no se dirige a los ancianos avanzados en edad quienes están convencidos de tener un conocimiento seguro debido a su excesivo amor propio y a que su alma está dominada por pasiones. Muchos de los que se proclaman filósofos padecen este tipo de enfermedad incurable en el alma llamada ignorancia y presunción. Sus vicios están validados por juicios erróneos, por una falsa sabiduría que es imposible de modificar por su misma presunción, cerrándoseles así toda posibilidad de curación. Aún más, Galeno establece los cincuenta años como el límite donde el alma perdería la posibilidad de ejercitarse y de liberarse de su afición. Pues argumenta que "si no se puede curar a alguien que ha tenido un tumor durante tres o cuatro años, ¿cómo se pueden curar las almas de tales ancianos cargadas de ignorancia y presunción, ese viejo tumor de treinta o cuarenta años?" (Galeno, 1997d, p. 79).

El entrenamiento de la parte lógica del alma depende para nuestro médico griego de los hábitos, del tiempo e incluso de la complexión humoral del sujeto. Hoy diríamos que la edad y el reforzamiento de una determinada conducta supone la pérdida de cierta plasticidad neuronal. La terminología y la evidencia experimental es inconmensurablemente distinta, pero Galeno (2003) no deja de ver la íntima vinculación que existe entre la funciones orgánicas y los hábitos humanos.

\section{CONCLUSIÓN}

En Galeno se aprecia el descubrimiento intracientífico que la enfermedad humana no puede ser explicada exclusivamente desde la realidad corporal. Sin perder de vista el objeto delimitado de su práctica médica entrevé los dinamismos cognitivos, pulsionales y morales que inciden en la physis humana.

En Diagnóstico y tratamiento de las pasiones del alma de cada uno y Diagnóstico y tratamiento de los errores del alma de cada uno, Galeno aborda lo que en un sentido propio entiende como enfermedad del alma. Estudia las pasiones, los errores cognitivos, los hábitos y costumbres morales, mas no lo hace en tanto

\footnotetext{
6 'Esfuérzate en contener su vehemencia (la de la pasión) antes de que aumente y resulte casi invencible. En ese caso, no podrás dominarla aunque lo desees y dirás después, como lo he oído de un amante, que quieres suprimirla pero que no puedes conseguirlo: nos rogarás en vano, como un hombre desesperado, ayuda para erradicar la pasión. Pues debido a su fuerza, algunas de las pasiones del cuerpo resultan incurables" (Galeno, 1997c, p. 28). En la página 37 escribe: "es necesario extirparla (a la pasión) antes de que llegue al término de su crecimiento y se vuelva incurable".
}

AlPHA No 48 (2019) PÁGS. 9-20. ISSN 0716-4254| 225 


\section{Teresa Gargiulo}

condicionantes del actuar moral sino como causas etiológicas primarias del enfermar humano. Su objetivo en dichos escritos no se reduce a "transmitir una enseñanza acerca de cómo llegar a ser "hombre de bien"” -así como asegura García Ballester (1972, p. 134)-, sino señalar los conflictos pulsionales que desencadenan propiamente las afecciones anímicas. En este sentido, la tesis que expone en Quod animi mores corporis temperamenta sequntur, en donde las disfunciones humorales son causa per accidens de las afecciones anímicas, se ve complementada por la tesis propuesta en estos dos últimos tratados; a saber, que los movimientos de las facultades del alma -sean estas de naturaleza moral o cognitiva- se erigen como la causa propia del enfermar anímico. Si se asume su doctrina hilemórfica como el eje antropológico de la medicina galénica, entonces es posible comprender la continuidad existente entre estos dos abordajes diversos acerca del enfermar humano.

El médico de Pérgamo no se limita a señalar la patente relación que existe entre la complexión humoral, los rasgos psicológicos y las condiciones morales de un individuo. Le preocupa fundamentalmente que la medicina tenga en cuenta estos dinamismos en sus mismos procesos curativos. En este sentido, su apelación a lo moral no supone en absoluto un distanciamiento respecto de las competencias epistemológicas de su práctica médica. Si se ocupa de ella es en tanto y en cuanto esta también se comporta como un posible agente causal del enfermar humano.

La medicina hipocrática suministró a la filosofía moral analogías que nutrieron el desarrollo de su especulación y le permitieron hablar de un alma saludable en los términos de virtud, del justo medio o de equilibrio entre sus partes. Entre los contemporáneos de Galeno esta simbiosis entre moral y medicina seguía evidentemente viva. No obstante, ello no es motivo para explicar como una mera metáfora la relación profunda que existe entre ambas en los escritos de Galeno. La dimensión moral del alma es parte de sus intereses clínicos porque ella afecta directamente a la salud del hombre. Pero no es la regulación moral de los actos el eje de su doctrina acerca de las enfermedades del alma. El exceso de las pasiones afecta al alma porque significa fisiológica, anatómica o funcionalmente una desproporción entre las facultades del alma. Su investigación anatómica-fisiológica de la estructura del alma sitúa la cuestión acerca de la salud del alma en límites antropológicos más amplios que las consideraciones estrictamente morales.

Una prueba más de ello es que a Galeno (2003) no le interesa resolver una cuestión que se presentaba comúnmente al griego como la fundamentación medular de la vida moral Se trata de la cuestión acerca de si el alma es inmortal y separable del cuerpo. Este desinterés puede explicarse por dos motivos. Primero -y tal como lo explica el mismo médico- porque se trata de un problema que excede las herramientas conceptuales y metodológicas de la medicina. Segundo, porque resolver dicha cuestión en nada contribuye al diagnóstico y tratamiento de las enfermedades del alma.

Galeno investiga acerca de la naturaleza del alma solo aquello que juzga relevante para diagnosticar y aplicar los remedios necesarios para restablecer en ella la 
salud. Entre los conocimientos necesarios para el ejercicio de la medicina no entra la cuestión acerca de la inmortalidad del alma, pero sí la distinción entre las distintas facultades del alma con sus respectivas sedes orgánicas así como la cuestión acerca de la virtud propia de cada facultad. Pues solo si se conocen las distintas partes del alma, se puede identificar la función lesionada y discriminar la mejor forma de curarla. Atendiendo a la naturaleza de cada parte se puede distinguir la virtud y el tratamiento que le corresponde a cada una. El médico debe conocer y diferenciar anatómica y fisiológicamente las partes del alma para poder diagnosticar y determinar las causas, el pronóstico y el tratamiento de este tipo de enfermedades.

Es útil para los médicos conocer el lugar [del alma hegemónica] para aplicar los remedios cuando la facultad lógica está dañada; pero los filósofos no utilizan este conocimiento ni para descubrir la diferencia entre las virtudes ni para el entrenamiento mismo. Porque si la parte hegemónica del alma está en la cabeza permitirá que podamos adquirir prudencia y templanza y justicia y virilidad (andreian) con una enseñanza y entrenamiento distintos que si está localizada en el corazón (Galeno, 2005, p. 16).

Esto nos permite sostener contra la tesis de Ballester que las enfermedades del alma no solo son objeto de interés de Galeno en cuanto filósofo moralista sino también del médico. Aquellos tratados en los que se ocupa del diagnóstico y tratamiento de las pasiones y de los errores del alma -a los que Ballester adjudica un carácter estrictamente moral- pueden revelársenos en este contexto como vías efectivas para que el hombre recupere el estado de salud, lo que es ciertamente el objetivo de su práctica médica.

\section{OBRAS CITADAS}

Boudon-Millot, Véronique (2009). "Galen's Bios and Methods: from ways of life to path of knowledge". En Galen and the World of Knowledge, Christopher Gill, Tim Whitmarsh \& John Wilkins (eds.), Cambridge: Cambridge University Press: 175-189.

Galeno (2016). De Sanitate Tuenda (San. Tu.). Sobre la conservación de la salud. Introducción, Traducción, Notas e Índices de Inmaculada Rodríguez Moreno. Madrid: Ediciones Clásicas.

- (2015). De Placitis Hippocratis et Platones (PHP). On the doctrines of Hippocrates and Plato. Thrid edition. 3 Vol., Edition, translation and commentary by Phillip de Lacy. Berlin: Akademie-Verlag.

— (2006). De symptomatum differentiis (Symp. Diff.) On the Differences in Symptoms. Ian Johnston (trad.). Galen on Diseases and Symptoms, Cambridge and New York: Cambridge University Press. 
(2003). Quod Animi Mores Corporis temperamenta Sequntur (QAM). Las facultades del alma siguen los temperamentos del cuerpo. Introd., trad. y notas de Juana Zaragoza Gras, Madrid: Gredos.

- (1997a). De Locis Affectis (Loc. Aff.). Sobre la localización de las enfermedades. Introducción de Luis García Ballester, Traducción y notas de Andrés Aparicio, Madrid: Gredos.

—_ (1997b). Art of Medicine, en Galen: Selected Works. Traducción. Introducción y Notas de P. N. Singer, Oxford, New York: Oxford University Press.

_ (1997c). De propium Animi Cuiuslibet Affectuum Dignotione et Curatione (Aff. Dig.) Galen: Selected Works, Ars. Medica (Ars Med.). Traducción. Introducción y Notas de P. N. Singer, Oxford, New York: Oxford University Press.

—_ (1997d). De Animi Cuiuslibet Peccatorum Dignotione et Curatione (Pecc. Dig.) Galen: Selected Works, Ars. Medica (Ars Med.). Traducción. Introducción y Notas de P. N. Singer, Oxford, New York: Oxford University Press.

García Ballester, Luis (2002). "Galen's medical works in the context of his biography". En Galen and galenism. Theory and medical practice from Antiquity to the European Renaissance. Arrizabalaga, Jon et al. (eds). Aldershot: Ashgate Variorum, 1-53.

_ (1996). "Alma y cuerpo, enfermedad del alma y enfermedad del cuerpo en el pensamiento médico de Galeno", Rev. Asoc. Esp. Neuropsiq. Vol. XVI, No 60: 705-735.

_ (1993). "On the Origin of the 'Six Non-natural Things' in Galen". En Galen und das hellenistische Erbe, Harig G. and Kollesch J. (eds.), Berlin: Springer:101-115.

_ (1972). "Alma y enfermedad en la obra de Galeno. Traducción y comentario del escrito Quod animi more corporis temperamenta sequuntur", Cuadernos Hispánicos de Historia de la Medicina y de la Ciencia, Ed. De la Valencia: Universidad de Granada.

Molina González, Liliana Cecilia (2012). Fisiología y Ética. Fundamentos Fisiológicos de la Psicología Moral en Galeno de Pérgamo, Doctorado en Lógica y Filosofía de la Ciencia, Universidad de Valladolid.

Moreno Rodríguez, Rosa (2013). "Ética y Medicina en la obra de Galeno", Dynamis 33-(2): 441-460.

— (1983). "El concepto de diáthesis pará phýsin (estado preternatural) en la patología de Galeno", Dynamis (Acta Hisánica ad Medicinae Scientiarumque Historiam Ilustrandam), Vol. 3: 7-27.

López Piñero José M., Morales Meseguer J. M. (1970). Neurosis y Psicoterapia. Un estudio histórico. Madrid: Espasa Calpe.

—_ (1966-1967). "Los tratamientos psíquicos anteriores a la aparición de la Psicoterapia”, Asclepio, 18-19: 457-481. 